European journal of American studies

Summer 2017, including Special Issue: Popularizing

Politics: The 2016 U.S. Presidential Election

\title{
The End of The Road
}

\section{Sean Hermanson}

\section{(2) OpenEdition}

Journals

Electronic version

URL: https://journals.openedition.org/ejas/12057

DOI: 10.4000/ejas. 12057

ISSN: 1991-9336

Publisher

European Association for American Studies

\section{Electronic reference}

Sean Hermanson, "The End of The Road", European journal of American studies [Online], 12-2 | 2017, document 7, Online since 01 August 2017, connection on 08 July 2021. URL: http://

journals.openedition.org/ejas/12057 ; DOI: https://doi.org/10.4000/ejas. 12057

This text was automatically generated on 8 July 2021 .

Creative Commons License 


\title{
The End of The Road
}

\author{
Sean Hermanson
}

Once there were brook trout in the streams in the mountains. You could see them standing in the amber current where the white edges of their fins wimpled softly in the flow. They smelled of moss in your hand. Polished and muscular and torsional. On their backs were vermiculate patterns that were maps of the world in its becoming. Maps and mazes. Of a thing which could not be put back. Not be made right again. In the deep glens where they lived all things were older than man and they hummed of mystery.

1 So closes The Road with a coda of haunting beauty that has garnered both praise and bewilderment. Alongside its intrinsic qualities, the passage is arresting for its contrast with the novel's relentless portrayal of the barbarism and deprivation that has consumed the world like wildfire. Yet despite the substantial literature devoted to it, nobody seems quite sure what to make of the ending, which also hums with mystery. Some find these final lines suggestive of renewal, though only vaguely (Kunsa 67-8). Others contend that it does little to ameliorate the novel's pessimism (Edwards 55; Gretlund 49-50). Still others find it offers both lamentation and "a small promise of hope" (Ellis 36), "strangely uplifting" (Luttrell 24), and "a recognition of what we have not yet lost, but still may " (Palmer, 66), while some pass it over in silence (IbarrolaArmendariz). As an admirer with a taste for puzzle solving, here I offer a new interpretation, which attempts to dispel its "torturous ambiguity" (Wilhelm 141) and reveal a surprisingly optimistic denouement.

2 My method is informed by what philosopher Steven Burns dubs the "best reading" approach which rejects "a commonplace in discussions of art and literature [namely] to claim that the greater a piece of writing, the richer a work is, the more interpretations it will sustain. I think that there is something wrong with this idea." As an alternative, he argues that "The richer and more detailed a work, the less likely it is to sustain ambiguity, and the more likely it is that a unified interpretation will prove to be the best one" (Burns, 160). In this spirit I shall attend closely to plot and place in keeping with the "central role that geography plays in the American imagination" (Jarvis, 6). This arguably suggests a firm contextualization of the ending in the Appalachian environments of the Smoky Mountains. The best reading approach also fits well with Wierschem's call for greater attention to the "Scientific McCarthy" (2) and is at least 
consistent with other perspectives including those emphasizing McCarthy's social commentary.

Additional major themes that have been well noted include references to the "ecological consciousness" (Walsh) in McCarthy's "wilderness aesthetic" (Guillemin). It seems plausible that The Road "mirrors the dystopian moment of its composition and publication" which was characterized by political failure and angst about looming environmental catastrophe (Walsh, 256). Several including Cant, Edwards, Palmer, Monbiot, and DeBruyn agree that McCarthy seems to be giving expression to disquiet about our relationship to the natural environment. Others have taken up religious and spiritual elements, starting with Ellis, Tyburski, Walsh, Wilhelm, Vanderheide, and Hungerford. Critics are also mostly united in finding a deep "ethical sensibility" defying McCarthy's seemingly nihilistic universe (Walsh, 274). Let it be acknowledged that the reading offered here is complementary to much in these analyses.

When it comes to the ending, however, even those who concede an air of hopefulness have difficulty making sense of it (Ellis; Wilhelm; Palmer; Walsh; DuMont), especially the apparent absence of any rationale for humans persevering (Palmer, 66; Gallivan, 104). My aim is to draw out the significance of mostly unnoticed positive elements, building towards a role for the closing paragraph, which is not best read as simply punctuating the novel's unflinching bleakness with an elegy to the devastated natural order. I hope to persuade that its function is most likely to help relieve uncertainty about The Road's most pressing questions of plot.

5 The dramatic tension turns on fate of the father and the boy, (the "pilgrims," (3)), and by way of synecdoche, human kind. Given these stakes, it's hard to accept that the only compensation for having invested in these characters and endured the hellish landscape is to be abandoned to "The ponderous counterspectacle of things ceasing to be" (274). In addition, McCarthy seems to continually prod us to make inferences about the important points.

6 By this I mean he neither starves the reader of what she hungers for, nor simply doles out answers. Instead the path is constantly set with opportunities to discover for oneself. The book is peppered with hints, though they tend to be rather subtle, even when it comes to its most central concerns. The nature of the cataclysmic Event that brings about humanity's ruin is left for us to guess at. The setting is also only implied, as is the nature of the father's illness. Yet in each case an explanation can be pieced together with attention and patience.

7 Consider the Event, which is sparsely described as "a long shear of light and then a series of low concussions" (52) coming at an apparently random moment: 1:17 a.m. In an interview, McCarthy states that it is described so minimally because it is unimportant to the story-humanity faces any number of existential threats, both selfcaused and exogenous, so it doesn't matter whether it is war, androcentric environmental disaster, super-volcano, or whatever. ${ }^{i}$ Given the quasi-religious theme of redemption, perhaps assigning humans responsibility for their downfall would make the most sense thematically, and this impression is perhaps supported by occasional

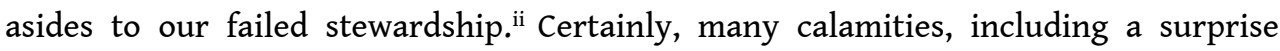
attack, might visit in the dead of night. Yet despite his coyness, notice that a supervolcanic eruption would not announce itself with a single shear of light witnessed hundreds, perhaps thousands, of miles distant. It simply couldn't happen. Meanwhile, the omnipresent ash cover blotting out the sun which now circles "like a grieving 
mother with a lamp" (32) could be caused in several ways, including nuclear exchange, though this would require dozens, if not hundreds, of individual detonations, and therefore many bright flashes and accompanying thuds.iii Other evidence indicating global cooling, tsunamis, ${ }^{\text {iv }}$ aftershocks, intact cities, and the absence of fallout or radiation all point in the same direction, quite unequivocally, towards a collision with a large solid body-either a stray comet or asteroid breaking up with multiple impacts. Only a meteor strike would also account for the massive fires, instantly disabled power and communications, and enormous dust clouds. The dense atmosphere would block sunlight and trigger conditions similar to nuclear winter. Given a sufficient drop in usable light energy, photosynthesis would go into steep decline, the food chain would collapse, and mass extinctions would transpire, such as massive fish die-offs due to the inability of phytoplanken to replenish oxygen (222). As a science-buff McCarthy is likely familiar with the general outline of these ideas, perhaps including famous works co-authored by Carl Sagan about nuclear war and global cooling. This line of reasoning requires a little familiarity with popular treatments of volcanoes, nuclear winter, etc., and is but one example of how McCarthy seems to nudge the reader to discover for herself what is going on.

8 This strategy is utilized again when it comes to the setting, which despite the confusion of numerous "geographically challenged" critics is undoubtedly the Southeastern United States (Morgan). Once again, the evidence is scanty, but appears to reward scrutiny, and is faithful to McCarthy's habit of "always 'carefully chart[ing] his characters' movements" (Kunsa 22 quoting Arnold 11). For example, the American locale is determined by the father's reference to the defunct "states" which the "interstates" they travel once connected. Others have offered very precise reconstructions of the characters' wanderings, most notably, Morgan (2008) who traces their route from Middlesboro, $\mathrm{KY}$ to the Atlantic coast. In between, the pilgrims traverse notable landmarks including the Cumberland Gap, Norris Dam, Knoxville, and Gatlinburg, before reaching the Newfound Gap in the Smoky Mountains. With several days more journeying they seem to come across Dry Falls near Highland, SC. At this point Morgan admits he becomes somewhat lost, though the "piedmont plain" lying ahead, along with architectural and other antebellum references, strongly suggests the interior of South Carolina. ${ }^{\mathrm{v}}$

9 Another example is that while the man's illness is never specified, beyond coughing up blood and general enervation, it is most likely a chronic respiratory infection due to inhalation of toxic dust, aggravated by starvation and exposure. That it is harmful to even breathe the air is evidenced by the ubiquitous use of masks and filters, and in one instance a full "biohazard suit" (60).

So it seems important aspects of the story, including the nature of the catastrophe that destroyed civilization, the location, and the father's illness, though only implied, are quite strongly established by way of sparing detail. The technique is perhaps gestured at in the use of the phrase "maps and mazes" (287) in the concluding paragraph. The reader's uncertainty about what is happening in the story is mirrored in and gives insight into the characters' own confusion about where they are headed. The father's roadmap is literally fragmented into a set of disordered leaves, which he can consult only after tedious reassembly (42). Despite these efforts, they are hopelessly lost and prolong their lives only because of good fortune. Though they do eventually reach the ocean, it is lifeless. As the well-equipped "veteran of old skirmishes" (281) who later 
rescues the boy understandably remarks, "I don't know how you made it this far" (283). The reader is also in danger of getting lost, but I contend, can find her way by attending carefully to the scraps of evidence.

11 This suggests achievement through struggle is an important theme, crucial both when it comes to the protagonists' personal survival and the reader's attempt at understanding. The characters must overcome the hostility of nature and other people, though occasionally they are relieved by fortuitous circumstance (or perhaps "rewarded"). Propitious or not, these windfalls deliver only a taste of the material abundance enjoyed by pre-disaster society, such as the Coca Cola they find in a vending machine (23). The waterfall (37), abandoned bunker (138), and derelict yacht (223), also only offer fleeting and insecure comfort. The found resources are soon to be exhausted and once again the characters will face starvation-the bunker is even compared to a grave (155). Meanwhile, there is constant anxiety that somebody very dangerous will come along, soon. It is only with the appearance of the self-reliant Veteran that any sense of genuine security is attained. The point seems to be that sustainable living won't be found by chance, and one has to take responsibility for making wise choices. Though it could be said that the boy is still only surviving thanks to luck, he must still take ownership of the decision to join the new group. We can also assume he will be expected to contribute. But if the boy finds refuge, it's because he's found a band of humans who have learned to survive. Similarly, the reader must also struggle to understand.

Actually, the novel is littered with clues about the boy's future and, as a proxy, the fate of human kind. There are three areas where this evidence seems to be concentrated: the concluding paragraph, the encounter with the Veteran, and the pilgrims' time spent in the mountains. Allow me to explain.

13 The ending is certainly a puzzler. The final passage is a meditation on our enchantment with nature, lost beauty, and the connection between a thing's preciousness and its being finite. This is something of a payoff. McCarthy appears to be saying everything must run its course (Cant 280) though this increases the significance of whatever we hold dear. Perhaps it is also implied that the boy dies along with the new group, since they also can only prolong their ultimate demise. Or perhaps there is no ending in the conventional sense, and the reader is left to conjecture possibilities. However, these ideas conflict with what else we know. The Veteran is suitably kitted, knowledgeable, and confident, and even echoes the father's reassurances by remarking, "You'll be all right" (283) vi His clothing is appropriate for cold weather. He is heavily armed. The emphasis on improvised shotgun shells indicates he is a builder, not just a scavenger. He must have shelter, tools, raw materials, and, of course, food. The Veteran is so flush he doesn't even mind discarding a priceless blanket to cover the body of the boy's father (286). But where does he subsist in the endless dead zone? While this worry might be left unanswered, let us continue to consider McCarthy's pattern of rewarding the thoughtful reader.

14 Among the final questions presenting themselves are these: Is the Veteran a friend or an enemy? Does the boy survive? Does humanity? If so, how? What do they eat? Where do they live? I suggest the starting point is to accept that the Veteran is the key to the ending.

One might wonder if the Veteran is just a hallucination seeing as the narrative sometimes detours into dream-like passages. The boy is alone and perhaps an 
unreliable narrator. In addition, the appearance of a strong adult male leading a "family" of sorts just when things are most desperate is perhaps too good to be true (and even miraculous, given the "three days" (281) it has taken for the new father to "rise"). Despite this, I think there's a better account. I submit that in the context of the scientific jigsaw puzzle McCarthy is offering, the introduction of the Veteran helps the reader appreciate ultimate causes and solutions of ecological collapse. Though not every disaster is foreseeable, or our responsibility, our response to crises is under direct human control and calls for initiative, courage, ingenuity, and, crucially, trust and cooperation.

16 A key point is that the man is described in terms the boy is unlikely to have conjured on his own. The Veteran bears a shotgun with "wax covered shells" (283) and is wearing a "ski parka" (281). As the boy has never seen a shotgun and, we may assume, doesn't know anything about skiing, it seems unlikely these details are merely aspects of hallucinatory wish fulfillment. But is it not a miracle the boy encounters his rescuers at just that moment? Not at all, since the Veteran appears to have been following the pilgrims for some time, though from a distance. We can gather that, prudently, the Veteran hesitated to approach because the father was suspicious of other people. He has taken an interest in them, but it was only shortly after the father dies that he decides to make contact. It is even mentioned that he is still wary of the gun the boy now holds (282).

What about the Veteran's motives? The initial impression given by his twisted face creates tension, but this may only be a residue of the father's paranoia. Tellingly, the Veteran keeps his word and expends a valuable blanket on the father's corpse "as the man had promised" (286). This seems most unlikely if he is just another "roadrat" (66) since the boy need not have known otherwise. It also partly vindicates the boy's previous observation that "If you break little promises you'll break big ones" (34) as well. Though not deductively certain, this is good evidence the Veteran can be trusted (it may even hint that McCarthy can be trusted not to deliberately misdirect the patient reader). As noticed by Ellis (37) he also passes on an easy opportunity to disarm the boy (285). He claims to have a woman and children in his care (the Veteran is a patriarchal archetype), so again the implication is that he is a provider and doesn't mean the boy harm. It seems reasonable to conclude he is not a cannibal and the boy is taken into his care, at least for a while. Confirming this, the woman is described as speaking with the boy "sometimes" (286), indicating time is passing and he is not only surviving but has gotten comfortable opening up to her. As they seem to have access to surplus resources and are interested in acquiring new members, it is natural to wonder how they survive and where they live. So against the doubts of some (e.g. Gretlund 49) the Veteran's group is benevolent and has been tracking the pilgrims. We know this because he mentions there was "some discussion about whether to even come after you at all" (283). Come after you from where? Perhaps we are not supposed to know, but let us consider the evidence.

18 The Veteran is wearing a gray and yellow ski parka. I'll return to the colors in moment, but first consider how emphasizing that it is a ski parka might be of special significance; by contrast, generic "parkas" are mentioned fifteen times, but a ski parka only once. This seems more than coincidental given that skiing is rather obviously suggestive of mountains. Another subtle hint is the mention of the Veteran's smelling of woodsmoke. Despite much of the landscape having been burned to cinder, "woodsmoke" is 
mentioned only four other times. The first time occurs soon after they've passed through a "resort town" (29) in the mountains next to "slopes and snow" identified by Morgan (2008) as Gatlinburg. "[I]n that high world" (31) they also encounter "A rich smell of woodsmoke," and observe "fires still burning high in the mountains and at night they could see the light from them deep orange in the soot-fall" (30). This is a bit curious as the "Burnt forests for miles along the slopes" (29) might suggest combustibles are in short supply.

Perhaps to settle doubts about the origins of these fires, lighting storms are igniting the "tinder-box ridges above them" (31) and as they walk through "a drifting haze of woodsmoke" they observe a stretch of "thin black trees burning like heathen candles... on a ridge overlooking the broad piedmont plain" (48). Further confirmation that lightning strikes are responsible is provided by the encounter with the thunder-burnt man, though notice this suggests there could be people living up there.

Eventually they reach a mill town where they spot the "palest wisp" (78) of smoke near some buildings. While investigating they detect "A faint smell of woodsmoke on the air" (79) though the town appears to be deserted. Having moved on to the outskirts, they hear a dog bark. They decide to sleep in a car under an overpass and later notice "bits of light that appeared at random on the night grid" (82). So somebody has taken residence in those buildings: suspicious given the distance they have moved from the forest fires. They return to search some houses and though they do not hear from the dog again, sure enough a "little boy" (84) is briefly sighted. There's no further appearance of woodsmoke until much later when the Veteran finally reveals himself. It is worth considering whether the boy, who seems snug in his wool coat "with the sleeves turned back" (by his caretaker), and the dog, an incredible rarity, belong to the Veteran's group. . $^{\text {vi }}$

Considering that the pilgrims' home region in the north is frozen over, unviable, the coastal plain is a wasteland, the cities and stops along the road are picked over, and the ocean is dead, the next question is: where can they go? The answer proposed here is: the mountains. Indeed, McCarthy appears to be making a sly joke about the Smoky Mountains! We can surmise the Veteran first noticed their campfire, or perhaps their tracks, as they travelled over the Newfound Gap. ${ }^{\text {viii }}$ The Veteran's caution is sensible in light of the father's agitated state of mind. Perhaps the Veteran has gone ahead and taken up temporary residence in the town in order to escape the dangerous fires ignited by lightning, though we should be cautious about overstating what can be inferred about his background.

My first thought was that there can be nothing but more waste and decay in the mountains in the form of skeletonized trees; however this reaction would be rash. There is wood for fires and shelter construction, plenty of water, and even security from marauders, who seem unlikely to wander upwards without a very good reason (consider the absurdity of the Red Phalanx (91) marching up the peaks, just out of curiosity). McCarthy implies ever so slightly that people avoided heights, "You could be smoked out" (82); perhaps this is another oblique reference to the woodsmoke they ought to be seeking. Yet the pilgrims witnessed no signs of life. Or did they? Might one 
of those fires "burning high in the mountains" (30) have been a campfire? They heard noises which they assumed, perhaps mistakenly, were just trees breaking on their own. Most importantly, the assumption that the mountains would be inhospitable to plant and animal life can be called into question.

Consider how the paucity of natural light is constantly emphasized. The father wishes at one point that he had a functioning light meter "he might use to average out readings for a few months" (213) so as to not to overlook even small differences that might indicate the overcast is dispersing. Interestingly, earlier in the mountains he noticed "The nights now only slightly less black" (32). Although the remark is apparently of no consequence, consider the implication: It means even the naked eye can discern a thinning of the ash at higher altitudes. This might suggest why McCarthy, who employs color carefully, takes unusual pains to describe the Veteran's parka as "gray and yellow" (281). It is tempting to interpret the specific sequencing of this color scheme as representing ash being supplanted by the sun's light breaking through, perhaps not completely, but just enough to sustain life. ${ }^{\text {ix }}$

If this seems too speculative, consider another subtle but hopeful sign towards the end of the story: "There were days when the ashen overcast thinned and now the standing trees along the road made the faintest of shadows over the snow" (102). This observation also goes nowhere, but let us pause to take in its possible significance. It marks a turnaround from the opening with "days more gray each one than what had gone before" (3) and the supposition of some readers that "the ash always floating in the air will eventually be all that remains" (DuMont, 56). The "wet gray flakes" are cleansing the atmosphere, though they work slowly. Given the wild mushrooms (40) and mealy (though edible) apples (121) the characters discover, the occasional reference to seeds $(118,120,122,132,136,216)$ is suggestive of a potential solar reawakening of (at least) vegetative life. On this score it is worth noting the bedrock of the food chain is very hard to kill off. For example, the phytoplankon serving as the basis of the marine food web can get by with so little sunlight it is found in darkened depths $200 \mathrm{~m}$ below the ocean's surface (U.S. Fish and Wildlife Service); microbial bacteria necessary for life have survived many previous disasters, including the oceans freezing over (Trefil). A single huge impact large enough to lower light levels below the threshold required for photosynthesis-about 2 watts/m2 according to Turco et al. (40) -would be monumental, although not without precedent in the history of life. ${ }^{\mathrm{x}}$ This brings me to the reason why the emergence of faint shadows might be so important. It is because for there to be sufficient sunlight for visible shadows the energy flux must be 10-20 times stronger than what's required for photosynthesis. ${ }^{x i}$ This reinforces my suspicion that the environment is healing and life "much older than man" (287) will move forward, though, no doubt, with radical changes, perhaps putting an optimistic twist on the otherwise wistful "thing which could not be put back. Not be made right again" (287). In short, my suggestion is that McCarthy is strongly hinting through subtle narrative details that the story begins with a catastrophic asteroid strike but concludes on the edge of an organic rebirth. It further seems that a certain kind of individual-personified by the resourceful swashbuckler who also "carries the fire" of human fellowship-is called for. The father's isolation of the boy has also played itself out and there must be a return to sociality and community if humanity is to renew itself. 

ective is being taken. While this might be the omniscient narrator, the vivacity of the memory, of holding the fish, taking in the intricate "vermiculate patterns," as well as the employment of smell, suggests instead the subjective experience of some individual. As the father has died, the reminiscence cannot be his. Against the arguments of Luce (81) that the narrative stance is thoroughly ambiguous, I find the use of the second-person supports Wilhelm's (141) suggestion that the boy is the speaker. Perhaps it as an older man, himself near death, or even a descendant of the boy recounting to his own children how humans survived on brook trout in the mountains until it was feasible to migrate elsewhere. Eventually the age of ash concludes and life begins anew and thus the final paragraph completes the story of humanity's passage through (another ${ }^{14}$ ) existential bottleneck. This is a parable of how a father and his world need to give way for there to be genuine renewal, laden with anxiety about the inevitable loss of hard-fought knowledge and experience. What kind of world will my son inherit?

This interpretation fits nicely with the structuring of the immediately preceding paragraphs where we witness a rapid transition in time, perspective, and the relationships depicted, moving from the dying father's point of view, to the boy's encounter with the Veteran, then on to his growing relationship with the new group, 
and finally to (perhaps) the end of his life passing on his experiences "from man to man through all of time" (286).

The cryptic phrase "maps and mazes" now becomes clearer. Humanity has reverted to an oral tradition of knowledge transmission, and as others have noted storytelling is perhaps the key "humanizing, redemptive agency in the novel, one of the last remnants of the culture" (Walsh, 265). The boy (or whomever it is) passes on his experiences, the "breath of God was his breath" (286) though we can no longer decipher the enigmatic patterns of the natural world. Our basis for understanding evolution and other knowledge has been lost along with thousands, perhaps millions, of species, and all those moldering books. And yet the tree of life has not been extinguished, though our pre-scientific ignorance of the living world is reasserted. Maybe this is a mixed blessing.

Other ironies and inversions come to mind. As noted by Wilhelm (132) their shopping cart makes a mockery of the former abundance once taken for granted, and strikes this author of a reversed version of Queequeg's coffin. Several times we are reminded that humanity has been reduced to literally consuming its own future (the consumption of seeds is another poignant example). ${ }^{15}$ McCarthy seems to be saying we imperil ourselves insofar as we are unable to think and act beyond our immediate self-interest. However, even with flawless management of one's life (and the world), things might go awry anyway. This is essentially conventional wisdom, packaged very unconventionally.

The boy is saved, and though the father's ingenuity can be credited, so must the Veteran's grasp of the stark contrast between ocean and mountain, death and life. The reader, meanwhile, is placed in an analogous epistemic position. The possibility of redemption from error and ignorance is lying in plain sight, though there is no instruction manual. The point seems to be that, while sometimes difficult, turning the details over (and over) in one's mind and decoding for oneself is more meaningful and satisfying than passive absorption.

Notes

i "Hollywood's favorite cowboy," The Wall Street Journal, Nov. 20, 2009. Note that technically McCarthy was only referring to the cinematic adaptation.

${ }^{i i}$ As we shall see, McCarthy appears to be sensitive to human-introduced invasive species.

iii In a "severe" scenario of 10,000 megatons-within human capacities during the Cold WarTurco et al. estimate that light levels would be lowered below the minimum required for photosynthesis, though only for a little over a month in the Northern Hemisphere. It stands to reason that the Event must have been much more powerful. Only a naturally occurring strike, such as the asteroid responsible for the end of the Cretaceous period with an energy profile on the order of 50,000,000 megatons, fits the bill.

iv "Finally they just sat by the side of the road and stared at what was before them. Roofs of houses, the trunks of trees. A boat. The open sky beyond where in the distance the sullen sea lagged and shifted" (274). There was also significant damage to the yacht "where hardware had been ripped out. Some terrible force to sweep the decks of everything" (223-4). Note that commercial EPIRB's (Emergency Position Indictating Radiobeacons, 240) came into wide use in the 1970s. As with the flare gun, the presence of the EPIRB found in the capsized yacht is one of several reminders of technology made obsolete by the absence of people.

v Morgan's conjecture that they see the little boy and hear the dog in Pendleton, SC is unsupported by the prominent skyline and other details suggestive of a larger city, perhaps along the lines of Augusta or Asheville. The identity of this city is unknown, though a summer 
visit to the Highlands area convinced this author that the bridge they find blocked by a jackknifed tractor trailer "eight miles or so" (42) from what is presumably Dry Falls is the remotely located but aptly named Iron Bridge, spanning the Chattooga River. Reconstructing the remainder of their journey without extensive local knowledge will be difficult.

${ }^{v i}$ An interesting inversion given that the father says the same thing while they discuss this second boy: "I'm afraid for that little boy" and the father replies, "I know. But he'll be all right" (86). Again just before he dies the father says "I think he's all right" (280). The irony is that the second boy (already in the company of the Veteran) is the one who is safe and his concern is better directed towards himself, for he is the lost boy!

vii Gretlund (49) accuses the filmmakers of a "ridiculous...rewrite" for daring to show a dog in the company of the Veteran. But there is no error if it is one and the same as the one heard in the mill town.

viii The Veteran may have used the safety of night to overtake them. This would explain why someone with a rubber tired vehicle passed within fifty feet of their "great fire...and had not even slowed to look...They could be good guys. Couldn't they?" asks the boy (103). However, shortly later the characters notice a wagon with rubber tires presumably used by cannibals (109).

ix of the 81 times the word "gray" appears, the vast majority (85\%) describe the fallen state of the physical environment especially the light, water, snow, and landscape. Human artifacts are so described only five times (including the parka). Suppose McCarthy is working with a basic palette of nine colors (primary, secondary, plus gray, black, and white). The probability of any random two-color pairing for the parka is therefore about $1.2 \%$, and for gray followed by yellow it is half that at less than $1 \%$. Hence, it is very unlikely that this unusual scheme, unique in its perfect fit with the suggested best reading here, was selected by chance.

$x$ See http://news.nationalgeographic.com/news/2013/13/130214-biggest-asteroid-impactsmeteorites-space-2012da14/

xi By the World Meteorological Association's "sunshine standard" the sun's energy flux must be at least $120 \mathrm{~W} / \mathrm{m} 2$ for it be bright enough to cast visible shadows.

xii See http://www.nps.gov/grsm/learn/management/upload/Sams-Creek-Report.pdf and http://www.nps.gov/grsm/learn/nature/fish.htm

xii As recently as 70,000 years ago the Toba super-volcano brought about conditions similar to nuclear winter resulting in a reduction of the human population to around 15,000 individuals. See http://phys.org/news/2010-01-humans-endangered-species.html

xiv The father's inchoate hopes for renewal are gestured at when he finds "Packets of seed. Begonia. Morning glory. He stuck them in his pocket. For what?" (112).

\section{BIBLIOGRAPHY}

Arnold, Edwin, T. "Blood \& Grace: The fiction of Cormac McCarthy." Commonweal 121.19 (1994): 11-16.

Burns, Steven. "Wittgenstein and Grillpazer." in Sascha Bru, Wolfgang Huemer and Daniel Steuer (Eds.) Wittgenstein Reading (pp.153-170). Berlin/Boston: De Gruyter (2013).

Cant, John. Cormac McCarthy and the Myth of American Exceptionalism. London: Routledge, 2007. 
De Bruyn, Ben. "Borrowed time, Borrowed World and Borrowed Eyes: Care, Ruin and Vision in Cormac McCarthy's The Road and Harrison's Ecocriticism." English Studies 91.7 (2010): 776-89. Print.

DuMont, Andy. "Luminous Deceptions: Contingent Community and Aesthetic Form in Cormac McCarthy's The Road." The Cormac McCarthy Journal 10.1 (2012): 56-75. Print.

Edwards, Tim. "The End of the Road: Pastoralism and the Post-Apocalyptic Waste Land of Cormac McCarthy's The Road." The Cormac McCarthy Journal 6 (2008): 55-61. Print.

Ellis, Jay. "Another Sense of Ending." The Cormac McCarthy Journal 6 (2008): 22-38. Print.

Gallivan, Euan. "Compassionate McCarthy?" The Road and Schopenhauerian Ethics." The Cormac McCarthy Journal 6 (2008): 98-106. Print.

Gretlund, Jan Nordby. "3 Cormac McCarthy and the American Literary Tradition: Wording the End." Intertextual and Interdisciplinary Approaches to Cormac McCarthy: Borders and Crossings 6 (2012): 41-51. Print.

Guillemin, Georg. The Pastoral Vision of Cormac McCarthy. College Station: Texas A\&M Press, 2004. Print.

Hungerford, Amy. Postmodern Belief: American Literature and Religion since 1960. Princeton: Princeton University Press, 2010. Print.

Ibarrola-Armendariz, Aitor. "Cormac McCarthy's The Road: Rewriting the Myth of the American West." European Journal of American Studies 6.3 (Special Issue 2011): 1-13. Print.

Jarvis, Brian. Postmodern Cartographies: The Geographical Imagination in Contemporary American Culture. New York: St. Martin's Press, 1998. Print.

Kunsa, Ashley. "Maps of the World in Its Becoming: Post-Apocalyptic Naming in Cormac McCarthy's The Road." Journal of Modern Literature 33.1 (2009): 57-74. Print.

Luce, Dianne C. "5 The Painterly Eye." Intertextual and Interdisciplinary Approaches to Cormac McCarthy: Borders and Crossings 6 (2012): 68-89. Print.

Luttrell, Daniel. "Prometheus Hits The Road: Revising the Myth." The Cormac McCarthy Journal 8.1. (2010): 20-33. Print.

McCarthy, Cormac. The Road. Pan Macmillan, 2006.

Monbiot, George. "Civilisation Ends With a Shutdown of Human Concern. Are We There Already?" The Guardian 30 October 2007. Print.

Morgan, Wesley G. "The Route and Roots of The Road." The Cormac McCarthy Journal 6 (2008): 39-47. Print.

Turco, Richard P., Toon, Owen B., Ackerman, Thomas P., Pollack, James B., and Sagan, Carl. (1984). "The Climatic Effects of Nuclear War." Scientific American 251.2 (1984): 33-43. Print.

Trefil, James. "When the Earth Froze." Smithsonian Magazine, December, 1999. Print.

Tyburski, Susan J. "'The Lingering Scent of Divinity' in The Sunset Limited and The Road." The Cormac McCarthy Journal 6 (2008): 121-8. Print.

U.S. Fish and Wildlife Service (1987). "Habitat Suitability Index Models: Muskellunge.”

Biological Services Program: U.S. Department of the Interior. Retrieved from http:// www.nwrc.usgs.gov/wdb./pub/hsi/hsi-148.pdf 
Vanderheide, John. "Sighting Leviathan: Ritualism, Daemonism, and The Book of Job in McCarthy's Late Work."The Cormac McCarthy Journal 6 (2008): 107-20. Print.

Walsh, Christopher J. In the Wake of the Sun: Navigating the Southern Works of Cormac McCarthy. Newfound Press, 2009. Print.

Wierschem, Markus. "The Other End of The Road: Re-Reading McCarthy in Light of Thermodynamics and Information Theory." The Cormac McCarthy Journal 11.1 (2013): 1-22. Print. Wilhelm, Randall S. “'Golden Chalice, Good to House a God': Still Life in The Road.” The Cormac McCarthy Journal 6 (2008): 129-46. Print.

World Meteorological Organization. Manual on the Global Observing System. WMO-No. 544. Geneva, 2003. Print.

\section{ABSTRACTS}

The closing paragraph of Cormac McCarthy's The Road hums with mystery. Some find it suggestive of renewal, though only vaguely. Others contend that it does little to ameliorate the novel's pessimism. Still others find it offers both lamentation and hopefulness, while some pass it over in silence. As an admirer with a taste for puzzle solving, here I offer a new interpretation revealing a surprisingly optimistic denouement.

\section{INDEX}

Keywords: McCarthy, The Road, ecocriticism, nature, Scientific McCarthy, the Smoky Mountains, brook trout 